\title{
Hormone Profile in Hypersexuality Women
}

\author{
Ahmed Al Awlaqi ${ }^{1}$, Khalid Alkhayat ${ }^{1}$, Guvan Akrawi ${ }^{1}$, Nasser Al Awlaqi ${ }^{1}$, Mohamed E Hammadeh ${ }^{{ }^{*}}$
}

\begin{abstract}
Hypersexuality refers to a clinical diagnosis used by mental health providers and researchers to describe a suddenly increased or extremely frequent sexual activity or sexual urges. The literature defines hypersexuality as a condition where affected persons exhibit excessive or unusual indulgence or concern with sexual activity. Sexologists have reported that hypersexuality can be a primary condition, or a symptom of the underlying medical sexual condition, such as a bipolar disorder, Parkinson disease, damaged kidney or impaired adrenal functions. The objective of the current review is to explore the hypersexual behavior in females and examine the role of sexual hormone secretion in proliferating the condition. Specific focus is to discuss how a hormonal imbalance in females could lead to hypersexuality if major glands in the body become impaired, including the adrenal cortex, the thyroid glands, pancreatic glands, and how medical conditions like cancer in these organs can also trigger hypersexual behavior. The study will also seek to verify if there is a link between medical conditions on the above organs and the normal secretion of sex hormones, which when triggered can cause an imbalance in hormone secretion resulting in excessive sexual urge and fantasies.

Keywords: Androgens, Adrenal glands, Bipolar disorder, Hypersexuality sex hormones
\end{abstract}

\section{Introduction}

Androgens are hormones present in both male and female. However, they are commonly found in men and are attributed to the cause of male character traits and reproduction growth. The main androgens are androstenedione and testosterone and in men, these hormones are present in higher levels as they play a very vital part in shaping the masculine traits. Other forms of androgens have also been reported, including dehydroepiandrosterone (DHEA), dihydrotestosterone (DHT), and DHEA sulfate (DHEA-S) (1). In females, the hormones are secreted in ovaries and fat cells (2,3). According to Abramovitz (1), the variation in production of these hormones in either men or women has significant consequences in the body regarding sexual expression. Case in point, hormonal imbalance results in hormonal disorder that affects the sexual behavior of a person.

As elaborate, the importance of the androgen hormone to the female body cannot be underestimated. As noted by Alkhalil et al (2), the regular sexual behavior in women highly depends on the normal production of this hormone. In agreement with these views, Allen et al (3) note that in adult females, androgen hormones regulate sexual behavior, as they are responsible for estrogen synthesis. Also, Yazici (4) has added that androgen hormones play a significant role in sexual satisfaction. Hence, what remains clear from the literature is the fact that the alteration in the level of production of these hormones will have a direct effect on the sexual desire of the woman and may lead to the hypersexual condition.

According to Bertherat and Bertagna (5), hypersexuali- ty simply means an excessive increase of libido resulting from some medical conditions that affect variation in sexual urge. The objective of the current review is to examine the common medical condition and the hormone profile that has been reported to trigger hypersexualityin women. In the year 2010, the American Psychiatric Association that defined and gave the symptoms of hypersexual disorder released a draft containing a list of five symptoms that a person may experience regardless of gender (6). These symptoms are not due to some medication or manic episodes but rather they are because of the disorder. They include:

- The individual is consumed by sexual fantasies and indulgence in planning for excessive engagement in sexual behavior ${ }^{[1]}$,

- Concurrent repetitions in these sexual activities in response to dysphoric mood state,

- Repetitive engagement in sexual fantasies, behavior, and urges in response to stressful events in his/her daily life,

- Unsuccessful efforts to control this repetitive sexual engagement or even reduce it, and

- Irresponsible of sexual engagement disregarding the risks posed for emotional and physical harm to themselves or the others.

The above underlying medical conditions, as Higgins et al (7) explain, cause excessive production of libido hormones in women, thus causing them to have that urge for excessive sexual indulgence. The current review presents and discusses the common reasons for the alteration in normal secretion of this hormone that is responsible for

Received 28 September 2015, Accepted 14 January 2016, Available online 7 February 2016

${ }^{1}$ Department of Obstetrics \& Gynecology, University of Saarland, Homburg/Saar, Germany.

*Corresponding author: Mohamed E Hammadeh, Department of Obstetrics \& Gynecology, University of Saarland, Homburg/Saar, Germany.

Tel: +49 68411628117, Email: mohamad.eid.hammadeh@uks.eu 
women's sex drive, rendering them hypersexual or rather have an excessive desire to have sex.

\section{Androgen Production}

In agreement with the views of the above authors, Beckmann (6) documents that in females, androgens are fashioned in the adrenal glands, adipose tissue and the ovaries. In elaboration, it is in these organs that there appears to be the extra-glandular production of testosterone. Excessive production of androgen may cause adrenal disorders, testosterone secretion tumors, which, as studies shows, may trigger hypersexuality causing hormones (6-8). Figure 1 and Table 1 below show the major site of androgen production.

\section{Adrenal Adenoma, Familial}

Adrenal adenoma is a noncancerous (benign) tumor that is in the adrenalin gland. According to Alkhalil et al (2), adrenalin tumor arises because of mutations, in particular, genes that are not known yet. That is why it is hypothesized that it is inherited in the family and this is further exhibited that it is found together with some common inherited diseases such as Carny complex.

In cases where the adrenal adenomas produce hormones, it is referred to as functioning. However, this term maybe confused to mean normal, but in fact, in such instances, Khazaal and Zullino (8) state that adrenal hormones produces an excessive amount of steroid hormones resulting in increased sexual behavior. On the other hand, if the adrenal adenomas do not produce any hormones it is known as non-functioning (10). However, in the case where the tumor is referred to as functioning, Series and Dégano (10) state that it secretes different hormones and, therefore, different symptoms may be exhibited. These hor-

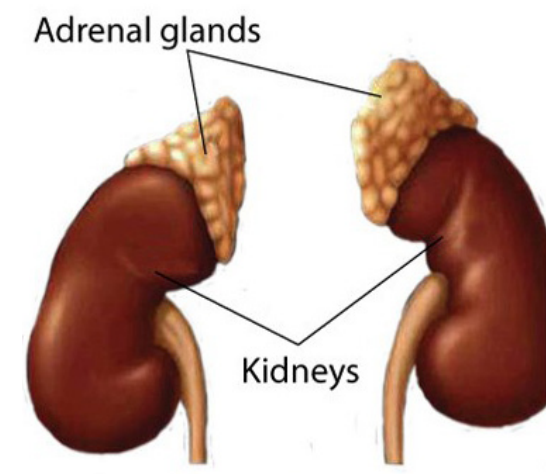

Figure 1. A Photo Showing Adrenalin Glands. Adapted from Linos and Van Heerden (9).

Table 1. Sites of Androgen Production ${ }^{\text {a }}$

\begin{tabular}{llll}
\hline Site & $\begin{array}{l}\text { DHEA-S } \\
(\%)\end{array}$ & $\begin{array}{l}\text { Androstenedione } \\
(\mathbf{\%})\end{array}$ & $\begin{array}{l}\text { Testosterone } \\
\text { (\%) }\end{array}$ \\
\hline Adrenal glands & 90 & 50 & 25 \\
Ovaries & 10 & 50 & 25 \\
Extraglandular & 0 & 0 & 50 \\
\hline
\end{tabular}

Abbreviation: DHEA-S, dehydroepiandrosterone sulfate.

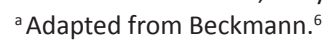

mones include androgenic steroids, corticosteroids, and aldosterone. Excessive secretion of androgenic steroids causes hypersexuality due to increases libido (11). These tumors are found by chance when there is a body scan for unrelated conditions. According to Clark et al (12), the majority of these tumors though are non-functional.

\section{Adrenalin Cancer}

In explaining about the adrenalin cancer (Figure 2), Bertherat and Bertagna (5) states that it is a rare disease that usually originates from the adrenalin glands. The adrenalin glands are situated at the topmost part of the kidneys and usually consist of two parts: the medulla (the inner layer) and the cortex (the outer layer) that usually function separately (11). The outer layer is responsible for the production of three major hormones. These hormones are cortisol (a glucocorticoid), DHEA and aldosterone. The inside layer (medulla) produces dopamine, norepinephrine and epinephrine.

In agreement with the above views, Lesser et al (14) note that this cancer usually occurs in young adults and causes overproduction of adrenal hormones and is certainly believed to be hereditary. The increases libido is due to excess secretion of androgenic steroids. According to Comandone (15), about one out of a million people develops adrenal cancer yearly worldwide. The symptoms for this cancer vary, but the most common are; moderate hypertension, constipation, excessive urination, headache, excessive thirst and frequent personality changes. The symptoms mentioned above are, but just a list of few symptoms but others are depending on the most secreted hormone by the gland $(14,16)$.

\section{Adrenal Cortex Diseases}

Haussermann et al (17) state that these diseases normally occur when the adrenalin gland seems not to produce enough hormones that they are expected. Figure 3 shows the functions of adrenal cortex in hormone secretion.

This condition is alternatively known as chronic adrenocortical insufficiency, primary adrenal insufficiency, oradrenonic adrenocortical hypofunction. Examples of this disease are Addison disease, adrenal fatigue, and Cushing syndrome. According to Jameson and Degroot (18), Addison disease is caused as a result of damaged adrenal

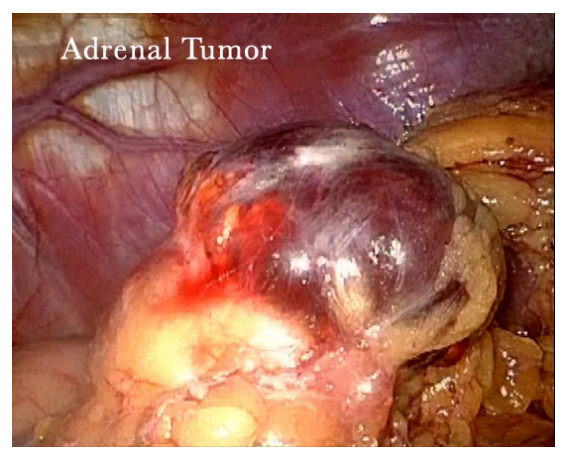

Figure 2. A Photo Is Showing Anexample of the Adrenal Tumor. Adapted from Fowler et al (13). 


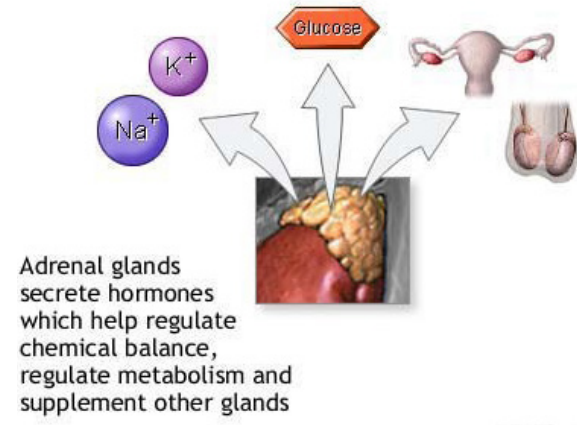

Figure 3. Depicting the Function of Adrenaline Glands in Hormone Secretion. Adapted from Fowler et al (13).

glands, which are known to produce the hormones that control the body's response to stress and aid in balancing the body salt and water. Because of the damage to adrenaline glands, there is reduced endurance and therefore, the patient, even though suffers from lower aldosterone secretion, lacks general self-control and therefore, may portray some symptoms of hypersexuality (19). Fong (20) also states that some of the symptoms of this disease include severe fatigue, loss of weight, weakness, increased pigmentation of the skin, nausea, salt cravings, low blood pressure, painful muscles and joints. Because this sickness is not apparent until almost $90 \%$ of the cortex is destroyed, some of the symptoms are ignored.

\section{Adrenal Cortex Neoplasms}

This tumor usually develops in the adrenal gland. Just as adrenal adenoma, the tumor may secrete hormones or may not. In explaining this further, Fowler et al (13) reveal that while secreting these hormones, the process may be excessive and, therefore, exhibit several symptoms depending on what hormones secreted most. The hormones that show these variations are made in the cortex and are the ones responsible for the increase variation of symptoms (21). The presentation of adrenal cortical neoplasm usually varies depending on the tumor size, and the status of tumor secretion. To Pollock (22), 20\% of the patients usually experience excessive androgen secretion.

The hormones that are affected because of these secretions are aldosterone, androgenic steroids and corticosteroids, which are manufactured in the cortex, the outside part of the adrenal gland (Figure 4). According to Moore and Puri (23), excessive secretion of androgenic hormones cause the increase of sexual urge and the patient finds herself indulging in excessive sexual activity and fantasy, thus being hypersexual. Other symptoms go with this medical condition such as loss of scalp hair due to excess corticosteroids secretion and increased body hair due to excess corticosteroids (24).

\section{Adrenal Gland Hyperfunction}

There are times where there is the excessive activity of the adrenaline gland. This activity causes excessive production of adrenal hormones. One or two of the hormones may be produced in excess, and therefore, the patient will

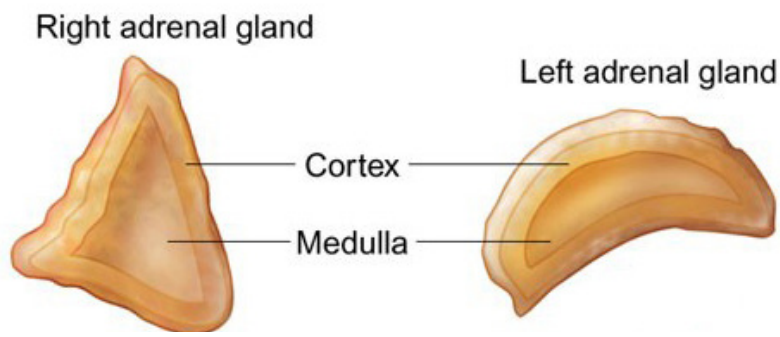

Figure 4. Showing the cortex and medulla of the adrenal glands where hormones are manufactured. Adapted from Fowler et al (13).

show symptoms according to the secretion of the hormones secreted. As Houck (25) further acknowledges, the hormones secreted by the gland includes androgenic steroids aldosterone, corticosteroids, norepinephrine and epinephrine. The tumor may cause increased activity of this adrenal gland. Gullette and Lyons (26) reveal that sometimes there can be cases of excessive stimulation of the glands and therefore, causing the increase of activity in the gland. Pituitary hormones are also responsible for simulation of adrenal gland activity. The increased libido that causes hypersexuality in women is because, during the excess activity of adrenaline gland, there may occur a scenario where excess androgenic steroids are secreted and therefore the behavioral change of the patient is realized (26).

\section{Adrenal Incidentaloma}

While performing an imaging examination, a tumor can be incidentally discovered in the adrenalin gland (27). The tumor may cause excessive secretion of adrenal hormones and therefore, causes the resulting symptoms or may also be asymptomatic. The discovered tumor may be benign or malignant. Benign tumors are tumors that lack the ability to spread since they do not attack neighboring cells (28). These tumors are non-cancerous in nature and according to Haussermann et al (17), part of the symptoms of adrenal incidentaloma is that there are excessive fat deposits at the back of the patient. The deposits are as a result of the excess release of corticosteroids, increased libido because of excess secretion of androgenic steroids and sometimes increased body hair due to excess corticosteroids. According to Garcia-Falgueras and Swaab, hypersexuality occurs when there is excess secretion of androgenic steroid hormones, which is responsible for the increase in libido. Increase in libido causes the patient to have an excess urge to sexual indulgence and sometimes lack control over the condition (9).

\section{Adrenocortical Carcinoma}

This disease is sometimes referred to as cancer of the adrenal cortex. This tumor, just as the previous ones, may be making more hormones than required (functioning) or making no hormones at all (nonfunctioning). Comandone (15) states that these hormones are made in large quantities, which may cause certain symptoms or signs of 
disorder in the patient's overall behavior. Linos and Van Heerden (9) also state that excessive secretion of hormones differentiates the symptoms portrayed by a patient. Symptoms that are exhibited in the early stage include increased body hair attributed to the fact that there was an increase secretion of corticosteroids, which also causes excess fats deposits at the back and sometimes loss of hair. When there is excess secretion of androgenic steroids, the patient will exhibit an increase in libido and therefore, develop hypersexuality (29).

\section{Bipolar Disorder}

Sometimes known as manic-depressive illness, bipolar disorder is a condition that causes the mood of the patient to have no proper direction. The mood keeps on changing back and forth between two distinct emotional states (30). In depression, the patient is sad, inactive and in a withdrawn state (31). On the other side, the mood of the patient may be extremely elevated and there are very high energy levels during this period, high alertness and a lot of excitement. However, according to Quinn (32), the patient may show some sign of endless talking or the rapid rush of ideas. These lead to the development of paranoia and delirium. This state can result in increased hormone release as depicted in Figure 5.

Most patients with bipolar disorder alternate between these moods and sometimes it can confuse the people who live with the patient. The depressed person may have thought of contemplating suicide attempts. Often the patient may not realize they are suffering from this disorder because the symptoms may be ignored as a normal way of life for these individuals $(33,34)$. There are several symptoms associated with this sickness. They include; persistent sad mood, appetite loss, overeating, weight gain, agitation, lack of energy, feeling of worthlessness, inappropriate guilt, difficulty in thinking, difficulty in concentrating, thought of suicide and death, chronic

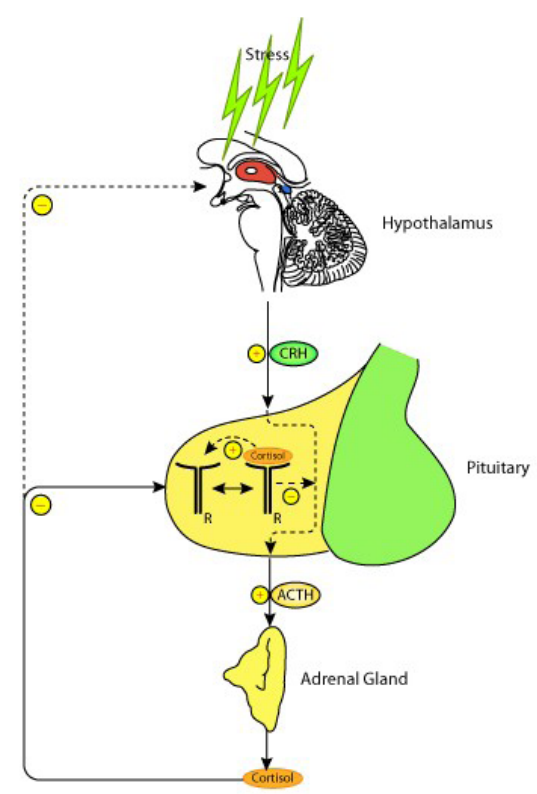

Figure 5. How Stress Can Cause Adrenalin to Release Hormone. In this case, is cortisol. Adapted from Quinn (32). pains oversleeping, sluggishness, insomnia among other negative thoughts. On the other hand, Hayat (35) notes that in case of mania the patient will exhibit these signs: spending spree, physical agitation, excessive involvement in goal-directed activities, distractibility, racing thoughts, fast-talking, excessive talking, decreased sleep need, unrealistic idea, grandiosity, over-inflated self-esteem, rebelliousness, irritability, inappropriately elevated mood and hypersexuality that is increased sex drive (36). During this period, the patient's estrogen hormones interact with many hormones and therefore, cause an imbalance that might be characterized to hypersexuality (37).

\section{HAIR-AN Syndrome}

Pal (38) states that Hair-An syndrome affects females and insulin resistance and overproduction of male hormones in female characterize it. When the body produces insulin, and the body does not use it very well, that condition is the one referred to as insulin resistance. Due to this resistance, the pancreas is forced to produce more insulin and therefore, high level of insulin causes the ovaries to produce excessive androgen that in this case causes acne, excessive hair growth, irregular periods and higher libido. The increased libido can cause the patient to be hypersexual and develop other complications later in life, such as diabetes, heart disease, excessive growth and high blood pressure (39).

\section{Hyperadrenalism}

Hyperadrenalism refers to a condition where the body produces an excessive level of adrenal hormones $(40,41)$. The symptoms depend on which hormone is involved and the degree levels in which is released. These hormones in the discussion are aldosterone, androgenic steroids, corticosteroids, norepinephrine and epinephrine (42). In cases where the excessive secretion of hormones involved is an androgenic steroid, the patient's libido level increases and eventually will exhibit signs of hypersexuality.

\section{Hyperandrogenism}

Hyperandrogenism is a condition where the body increases the body's male sex hormones. A woman secreting these hormones will exhibit male features such as breaking of voice, the growth of air changes in menstrual cycles and sometimes hypersexuality (43). Hyperandrogenism is a condition whereby the body makes an excessive amount of androgens, a hormone responsible for increased libido. Therefore, as Mushlin and Greene (44) state, the female patient will start showing signs of hypersexual tendencies.

\section{Hypertryptophanemia}

Hypertryptophanemia is a rare disease, but some of the symptoms include hypersexuality that is characterized by the presence of high levels of blood tryptophan. Some of the symptoms include; aggressive behavior, stuttering, development delay, adducted thumbs, limited elbow extension, loose joints, joint pain, absent femur bone, flat foot, absent ulnar bone, mood swings, impaired vision, 
strabismus, myopia, weak eye muscles, speech problems, behavioral problems, excessive sweating and hypersexuality (45).

\section{Kluver-Bucy Syndrome}

This rare behavioral impairment is characterized by inappropriate behaviors that are sexually related. Some of these patients turn to exhibit some abnormal characters like mouthing of objects and homosexuality. Other signs include loss of anger and normal fear traits, distractibility, dementia, memory loss, lack of ability to identify object visually and hypersexuality $(46,47)$. This disorder is associated with anterior temporal lobes damage of the brain and (42) in his text shows that he causes of this disorder have been connected to head trauma, maybe caused by an accident or herpes encephalitis.

\section{Mania}

Mania is the feeling of being high and euphoric. People with this disorder are overexcited, hyperactive or frantic. Their thought and speech are often fast and are fragmented because of frequent tumbling against itself caused by overall crisscrossing of ideas and thoughts. Cycling between this condition and abrupt depression is an indication of the bipolar disorder. Some of the symptoms according to Noggle et al (46) include, grandiosity, physical agitation, spending spree, distractibility, racing thoughts, fast talking, excessive talking, decreased sleep need, unrealistic idea, grandiosity, recklessness, fast moving, increased appetite, increased use of alcohol, over-inflated self-esteem, rebelliousness, irritability, inappropriate elevated mood and hypersexuality (47).

\section{Puberty}

Puberty is the physical and sexual maturation in adolescent $(1,35,48)$. The signs and symptoms of puberty include growth spurts, acne and maturation of the internal organs, increased appetite and menarche. Some of the mental and emotional changes include moodiness, emotional changes, anxiety, clumsiness, irritability and increased libido. The increased libido may cause hypersexuality behavior $(49,50)$.

\section{Sertoli-Leydig Cell Tumors}

Sertoli-Leydig cell tumors is a form of ovarian cancer where there are excess male hormones produced by the cancerous cells. The symptoms that come with this disorder include painful sex, fatigue, enlarged clitoris, acne, infrequent menstrual periods, pelvic pain and pelvic mass, reduced breast size, and increased libido. The increased libido is due to excessive androgenic hormones $(42,50)$.

\section{Conclusion}

In conclusion, a woman's sexual desires are altered when there is an alteration of androgens produced in the woman's body. Excessive reproduction of this hormone causes an increase in woman's libido and, therefore, causes her to urge for sexual indulgence. Hypersexuality is a condition whereby the patient exhibits signs of being consumed by sexual fantasies and indulgence in planning for excessive engagement in sexual behavior concurrent repetitions in these sexual activities in response to dysphoric mood state. Also, as Reiser and Thomson (48) reveal, other signs include repetitive engagement in sexual fantasies, behavior, and urges in response to stressful events in his/her daily life, unsuccessful efforts in to control this repetitive sexual engagement or even reduce it without much success. The irresponsibility of sexual engagement disregarding the risks posed for emotional and physical harm to themselves or the others (4).

This, as Souhami and Tobias (37) explain, may be because of medical condition such as, adrenal adenoma, adrenalin cancer, adrenal cortex diseases, adrenal cancer, adrenal gland hyperfunction, adrenocortical carcinoma, bipolar disorder, HAIR-AN syndrome, functioning pancreatic endocrine tumor, hypertryptophanemia, hyperadrenalism, hyperandrogenism, Kluver-Bucy syndrome, mania, puberty and sertoli. All of the above can be treated if early detected in the life of a patient. The biggest challenge is that most of these symptoms are ignored and the patient may not feel free to share them having the fear of stigmatization and self-ego. Some of the above conditions can result inthe loss of life and other chronic sicknesses.

\section{Ethical Issues}

Not applicable.

\section{Conflict of Interests}

The authors declare no conflict of interests.

\section{Financial Support}

The researchers received no financial support or grant from any funding agency in the public and commercial sectors.

\section{Acknowledgments}

None to be declared.

\section{Endnote}

Those sexual activity, may be masturbation, sexual involvements that is not normal but in its excess. Psych Central.com. 2013. Symptoms of Hypersexual Disorder (Sex Addiction) - Psych Central. [online].

\section{References}

1. Abramovitz M. Diseases and Disorder. In: Abramovitz M. Bipolar Disorder. Detroit: Lucent Books; 2005:9395.

2. Alkhalil C, Tanvir F, Alkhalil B, Lowenthal DT. Treatment of sexual disinhibition in dementia: Case reports and review of the literature. Am J Therapeutics. 2004;11(3):231-235. doi:10.1097/00045391200405000-0001.

3. Allen A, King A, Hollander E. Obsessive-compulsive spectrum disorders. Dialogues Clin Neurosci 2003;5(3):259-71. doi:10.1159/000321070. 
4. Yazici M. Ovarian Mucinous Cystadenomas in Childhood. In: Bardos AP, editors. Trends in Ovarian Cancer Research. New York: Nova Science Publishers; 2004:139-162.

5. Bertherat J, BertagnaX. Pathogenesis of adrenocortical cancer. Best Practices Res Clin Endocrinol Metab. 2009;23(2):261-271. doi:10.1016/j.beem.2008.10.006.

6. Beckmann CR, ed. Obstetrics and Gynecology. 2nd ed. Philadelphia: Lippincott Williams \& Wilkins; 2010.

7. Higgins A, Barker P, Begley CM. Hypersexuality and dementia: dealing with inappropriate sexual expression. Br J Nurs. 2004;13(1):1330133-4. doi:10.12968/bjon.2004.13.22.17271.

8. Khazaal Y, Zullino DF. Topiramate in the treatment of compulsive sexual behavior: a case report. BMC Psychiatry 2006;6:22. doi:10.1186/1471-244X-6-22.

9. Linos D, Van Heerden J, editors. Adrenal Glands, Diagnostic Aspects and Surgical Therapy. Berlin: Springer; 2005.

10. Series H, Dégano P. Hypersexuality in dementia. Adv Psychiatr Treat. 2005;19(6):424-431. doi:10.1192/ apt.11.6.424.

11. Clark OH, ed. Endocrine Tumors. London: Hamilton, B.C. Decker; 2003.

12. Clark O, Duh Q, Kebebew E. Thyroiditis. In: Clark O, Duh Q, Kebebew E, eds. Textbook of Endocrine Surgery. Philadelphia: Elsevier Saunders; 2005.

13. Fowler CJ, Panicker JN, Emmanuel A. Pelvic Organ Dysfunction in Neurological Disease: Clinical Management and Rehabilitation. Cambridge: Cambridge University Press; 2010.

14. Lesser JM, Hughes SV, Jemelka JR, Griffith J. Sexually inappropriate behaviors. Assessment necessitates careful medical and psychological evaluation and sensitivity. Geriatrics. 2005;60(1):34. doi:10.1037/0735-7028.28.1.58.

15. Comandone A. Rare Tumors of Male Genital Tract. In: Comandone A. Chemotherapy Regimens in Rare Solid Tumors. Torino: SEEd Srl; 2011:41-54.

16. Nosé V. Diagnostic Pathology: Breast. 1st ed. Salt Lake City, Utah: Amirsys Publishing; 2012.

17. Haussermann P, Goecker D, Beier K, Schroeder S. Low-dose cyproterone acetate treatment of sexual acting out in men with dementia. Int Psychogeriatrics. 2003;15(2):181-186. doi:10.1017/ S104161020300886X.

18. Jameson JL, Degroot L. Endocrinology: Adult and Pediatric. 7th ed. Philadelphia: Saunders, Elsevier; 2010.

19. Flück CE, Miller WL. Disorders of the Human Adrenal Cortex. Basel: Karger; 2008.

20. Fong TW. Understanding and managing compulsive sexual behaviors. Psychiatry (Edgmont). 2006; Nov: 51-58.

21. Ellis L, Hellberg J. Fetal exposure to prescription drugs and adult sexual orientation. Pers Individ Dif. 2005;38(1):225-236. doi:10.1016/j.paid.2004.04.004.
22. Pollock R. Advanced Therapy in Surgical Oncology. Hamilton, Ontario: BC Decker Inc; 2008.

23. Moore D, Puri B. Textbook of Clinical Neuropsychiatry and Behavioral Neuroscience. London: Hodder Education; 2012.

24. Lerma EV, Berns JS, Nissenson AR. Current Essentials: Nephrology and Hypertension. New York: McGraw-Hill Medical; 2012.

25. Houck JA. Hot and Bothered: Women, Medicine, and Menopause in Modern America. Cambridge, MA: Harvard University Press; 2006.

26. Gullette DL, Lyons MA. Sexual sensation seeking, compulsivity, and HIV risk behaviors in college students. J Community Health Nurs. 2005;22(1):4760. doi: 10.1207/s15327655jchn2201_5.

27. Fischer J, Bland K, Callery M. Mastery of Surgery. Volume 1. Philadelphia: Lippincott Williams \& Wilkins; 2006.

28. Fagan PJ. Sexual Disorders: Perspectives on Diagnosis and Treatment. Baltimore, Maryland: JHU Press; 2004.

29. Gizewski ER, Krause E, Schlamann M, et al. Specific cerebral activation due to visual erotic stimuli in male-to-female transsexuals compared with male and female controls: an fMRI study. J Sexual Med. 2009;6(2):440-448. doi:10.1111/j.17436109.2008.00981.x.

30. Leonard B, Jovinelly J. Bipolar Disorder. New York: Rosen Publishers; 2012.

31. Kiesbye S. Bipolar disorder. Farmington Hills, MI: Greenhaven Press/Gale Cengage Learning; 2010.

32. Quinn B. Mental Health. In: Quinn B, ed. Bipolar Disorder. Hoboken, NJ: John Wiley \& Sons; 2007:1137.

33. Garcia-Falgueras A, Swaab DF. A sex difference in the hypothalamic uncinate nucleus: relationship to gender identity. Brain. 2008;131(12):3132-3146.

34. Garcia-Falgueras A, Pinos H, Collado P, et al. The role of the androgen receptor in CNS masculinization. Brain Res. 2005 Feb 21;1035(1):13-23. doi:10.1016/j. brainres.2004.11.060.

35. Hayat M. Cancer Imaging. Amsterdam: Elsevier, Academic Press; 2008.

36. Sabolch A, Feng M, Griffith K, Hammer G, Doherty G, Ben-Josef E. Adjuvant and definitive radiotherapy for adrenocortical carcinoma. Int J Radiat Oncol Biol Phys. 2011;80(5):1477-1484. doi:10.1016/j. ijrobp.2010.04.030.

37. Souhami R, Tobias J. Cancer and its Management. 2nd ed. Oxford: Blackwell Science Ltd; 2005.

38. Freeman R. The role of the adrenal glands in the hyperandrogenism associated with polycystic ovarian syndrome. In: Pal L, ed. Polycystic Ovary Syndrome: Current and Emerging Concept. Dordrecht: Springer; 2013.

39. Lederman R. Tarascon Internal Medicine \& Critical Care Pocket Book. Burlington, MA: Jones \& Bartlett Learning; 2011. 
40. Hirneise L. Chemotherapy Heals Cancer \& the World is Flat. Germany: Atlasbooks Dist Serv; 2008.

41. Iemmola F, Ciani AC. New evidence of genetic factors influencing sexual orientation in men: female fecundity increase in the maternal line. Arch Sex Behav. 2009;38(3):393-399. doi:10.1007/s10508-0089381-6.

42. O'Connell T, Movalia M. Brochert's Crush Step 2. London: Elsevier Health Sciences; 2012.

43. Mendez MF, O'Connor SM, Lim GT. Hypersexuality after right pallidotomy for Parkinson's disease. J Neuropsychiatry Clin Neurosci. 2004;16(1):37-40. doi:10.1007/s11194-007-9045-4.

44. Mushlin S, Greene H. Decision-making in Medicine. Philadelphia, PA: Mosby Elsevier; 2010.
45. Nawar R, Aron D. Adrenal incidentalomas-a continuing management dilemma. Endocr Relat Cancer. 2005;12(3):585-598. doi:10.1677/erc.1.00951.

46. Noggle C, Dean R, Horton A. The Encyclopedia of Neuropsychological Disorders. New York: Springer; 2012.

47. Penzias A. Current Reproductive Endocrinology. Philadelphia: WB Saunders; 2000.

48. Reiser R, Thompson L. Bipolar Disorder. Cambridge, MA: Hogrefe; 2005.

49. Savic-Berglund I. Sex Differences in the Human Brain. Salt Lake City, UT: Elsevier; 2010.

50. Smith R, Netter F, Smith R. Netter's Obstetrics and Gynecology. Philadelphia, PA: Saunders Elsevier; 2008.

Copyright (c) 2016 The Author(s); This is an open-access article distributed under the terms of the Creative Commons Attribution License (http://creativecommons.org/licenses/by/4.0), which permits unrestricted use, distribution, and reproduction in any medium, provided the original work is properly cited. 